\title{
Evaluating the effect of Coriandrum sativum syrup on being migraine-free using mixture models
}

\author{
Samaneh Mansouri ${ }^{1}$, Iraj Kazemi ${ }^{2}$, Ahmad Reza Baghestani*3(D), Farid Zayeri ${ }^{1}$, Zahra Ghorbanifar ${ }^{4}$ \\ Received: 19 Jun 2018 \\ Published: 6 May 2020
}

\section{Abstract}

Background: Coriandrum sativum (coriander) is prescribed as a treatment for headache in traditional Persian medicine. Several investigations have been carried out to find the medicinal properties of this plant. However, no study has evaluated the effectiveness of this plant on becoming migraine-free.

Methods: Sixty-eight migraineurs were randomly allocated to two equal groups of intervention and control. Each received $500 \mathrm{mg}$ of sodium valproate in addition to $15 \mathrm{~mL}$ of coriander or placebo syrup three times a day. We followed subjects and recorded their migraine duration in the $1^{\text {st }}, 2^{\text {nd }}, 3^{\text {rd }}$, and $4^{\text {th }}$ weeks. We applied an appropriate statistical model so as to consider special features of the data, which led to more accurate results using SAS 9.4

Results: Our findings showed that the probability of being migraine-free was not only considerably higher in final weeks of the study $(p<0.001)$ in all patients of the intervention group than placebo group, but it was also significantly higher in patients less than 30 years of age compared to patients older than 30 years old. Migraine duration in migraineurs using coriander syrup reduced considerably during the study $(\mathrm{p}<0.001)$.

Conclusion: The finding of this study revealed that coriander has a significant effect both on the probability of being migraine free and the duration of migraine attacks. Its effects were more significant during the final weeks of study.

Keywords: Migraine headache, Coriandrum sativum, Herbal drug, Clinical trial, Mixture model

Conflicts of Interest: None declared

Funding: None

*This work has been published under CC BY-NC-SA 1.0 license.

Copyright $₫$ Iran University of Medical Sciences

Cite this article as: Mansouri S, Kazemi I, Baghestani AR, Zayeri F, Ghorbanifar Z. Evaluating the effect of Coriandrum sativum syrup on being migraine-free using mixture models. Med J Islam Repub Iran. Med J Islam Repub Iran. 2020 (6 May);34:44. https://doi.org/10.47176/mjiri.34.44

\section{Introduction}

An extremely common symptom throughout the world is headache (1), and migraine as a third most common disorder is the second most common type of headache (2). Near $15 \%$ of the general population are affected by mi-
Corresponding author: Dr Ahmad Reza Baghestani, baghestani@sbmu.ac.ir

1. Department of Biostatistics, Faculty of Paramedical Sciences, Shahid Beheshti University of Medical Sciences, Tehran, Iran

2. Department of Statistics, Faculty of Sciences, University of Isfahan, Isfahan, Iran

3. Physiotherapy Research Center, Department of Biostatistics, Faculty of Paramedical Sciences, Shahid Beheshti University of Medical Sciences, Tehran, Iran

4. Persian Medicine Department, School of Medicine, AJA University of Medical Sciences, Tehran, Iran $\uparrow$ What is "already known" in this topic:

Although prescribed chemical drugs have considerable positive effects on reducing migraine duration, their complications and side effects are not negligible. Coriander, as a herbal medicine, could have a significant effect on reducing migraine duration. However, becoming migraine-free is more important than reducing migraine duration, due to the fact that migraine is a chronic disease and imposes a great burden to the health system and society.

$\rightarrow$ What this article adds:

This paper showed that the probability of becoming migraine-free in the intervention group is significantly higher than the control group. Moreover, coriander has a more healing impact on migraineurs younger than 30 years old. The positive effect of coriander on migraineurs without aura was considerably higher than patients without aura. These results can only be obtained through a more appropriate and sophisticated statistical method which has been applied in this article. 
graine during their lives, among whom $75 \%$ are women. Migraine attacks can cause functional disability in more than $90 \%$ of migraineurs (3). There are abundant preventive treatments that are prescribed for patients with migraine. However, many studies have illustrated that these chemical drugs have various complications, such as constipation (4). Tremor (5), hair loss, and weight gain (6), profuse sweating (7), depression and orthostatic hypotension (8). Traditional therapies are applicable wherever conventional medicine is not able to treat the chronic disease effectively and without side effects (9).

Use of herbal medicine during the last decades has increased not only in developing countries, but also in developed ones, and it is being encouraged by World Health Organization (WHO), especially in chronic disease (10). Headache treatment in traditional Persian medicine dates back to the $6^{\text {th }}$ century BC (11). One of the prescriptions of ancient Persian practitioners was Coriandrum sativum (C. sativum, coriander) fruit (12). Several investigations have been carried out to find the medicinal properties of this plant. They reported that coriander has antioxidant (13), and anxiolytic (14), effects. Compared with standard antioxidant-ascorbic acid-the antioxidant activity of coriander is remarkably superior (15).

It has been shown that coriander contains micronutrient elements, which are well under the permissible limits determined by $\mathrm{FAO} / \mathrm{WHO}$ for human and could be suggested as a supplement (16). Numerous in vitro and in vivo studies conducted to investigate the pharmacological effects of coriander have illustrated that this plant has a great number of medicinal properties, such as antimicrobial, anti-inflammatory, anti-cancer, and analgesic activities (17). In addition, coriander is nutritionally valuable due to its high level of vitamin $\mathrm{C}$, folate, vitamin $\mathrm{A}$, vitamin B12, and polyphenols $(18,19)$.

Moreover, Linalool which is found in Coriander seed oil (20), has considerable effects on alleviating central nervous system disorders (21). An in vitro study on rats indicated that coriander essential oil significantly improves spatial memory performance (22). It is also shown that linalool has sedative effects on human subjects (23), which can explain the headache-relief effect of coriander (24).

As alluded earlier, impairment of daily activities, as well as less work capacity and comorbid disorders, caused by adverse effects of conventional treatments, impose substantial individual and social burden in almost all migraineurs. Therefore, using preventive herbal medicine with significantly lower cost and fewer side effects could be a better choice.

Despite a large number of studies carried out on migraine, the effectiveness of herbal drugs on migraine attacks has received less attention. We have not found any published papers on assessing the effect of coriander on becoming migraine-free during our literature review. For these reasons, we decided to conduct a study with two main purposes: first, determining the effectiveness of coriander on the duration of migraine attacks; second, assessing the effect of this plant on being migraine-free. We also compared the risk of occurrence of migraine attacks in migraineurs younger than 30 years old with migraineurs older or equal to 30 years old.

To reach these goals, a placebo-controlled clinical trial study has been conducted on 68 migraineurs who randomly received coriander or placebo syrup in addition to 500 mg of sodium valproate. The number and duration of their migraine attacks have been recorded on a weekly basis for 4 weeks.

A variety of statistical methods have been proposed to analyze the longitudinal data, including generalized linear mixed models or marginal models. However, these approaches do not consider all features of the data, such as skewness and excess zeros. Two-part models, however, can deal with these characteristics via dividing models into two parts, each of which considers one of these features. Compared with other models, using two-part model is a more general approach in a generalized linear mixed models framework. In this study, we applied these models not only to assess the effect of coriander on the reduction of duration and frequency of migraine attacks, but also to assess the probability of becoming migraine-free after undergoing this traditional treatment.

\section{Methods}

Data: In this article, we collected data during a prospective, two-arm, randomized, triple-blind, placebocontrolled trial study. Sixty-eight migraineurs were randomly allocated into two equal groups - 34 patients in each group - of intervention and control using the random permuted blocks of size 4 , in a 1:1 ratio for randomization. Patients were between 18 to 45 years of age. The patients, physicians, and data analyst were unaware of each group's treatment as it was a triple-blind study. The study was conducted in accordance with the Declaration of Helsinki and was approved by the Ethics Committee of Shahid Beheshti University of Medical Sciences. The reference number of ethical approval was $400 / 876$. The protocol was registered in the Iranian registry of clinical trials and received the registration number: IRCT 2012122511876 N1. Subjects were informed about the aim of the study before recruitment. They also signed an informed consent form.

Among 135 patients with migraine attack who referred to the neurology clinic of Shohadaye-Tajrish hospital, Tehran, Iran, 87 patients with inclusion criteria were selected. Of these patients, 19 individuals refused to participate in our study. The inclusion and exclusion criteria in all patients were assessed by a neurologist. Our population was migraineurs having migraine according to the international headache society diagnostic criteria for at least 1 year with at least four attacks per month. Pregnant women or those with the decision to become pregnant and lactating females were not allowed to take part. Patients with concurrent herbal or chemical treatment were not included in the study. Serious medical problems, such as cardiac disease or diabetes, were also considered as exclusion criteria. Also, People suffering from other kinds of headaches were also excluded.

Participants received $500 \mathrm{mg}$ of sodium valproate in both groups. Based on their allocation to each group, they 
also received $15 \mathrm{~mL}$ of placebo or coriander fruit syrup three times a day for one month.

Having the total essential oil of dried coriander extracted we used a Clevenger-type apparatus. Gas chromatography (GC) and GC-mass spectrometry (GC-MS) methods have been used for analyzing. Its major components were $82 \%$ linalool, $6 \%$ geraniol, $5 \% \alpha$-pinene, $3 \% \beta$-pinene and $1.5 \%$ thymol. To prepare the syrup total evaporated ethanol extract of coriander fruit with $100 \mathrm{mg}$ evaporated ethanol extract for each $5 \mathrm{~mL}$ of syrup in the base of sucrose pharmacopeia syrup with brix of over $70 \%$ was used. For placebo, the same appearance, packaging and pharmacopeia syrup formula without coriander fruit extract was used. The placebo syrup was produced with the liquid-liquid method.

For assessing quality control, syrups were produced by a pharmacologist. One placebo syrup and one coriander syrup were stored as controls. At each step of syrups' production, both placebo and coriander syrups were compared with their controls. For assessing quality assurance, patients were evaluated and followed with a specialist through a pre-specified questionnaire. At the end of each week, their performance was given to the relevant professor.

Initially, in addition to the duration of migraine attacks at baseline, their basic characteristics, and demographic information were recorded. Researchers asked patients to write the migraine attacks' durations each week for four weeks. At the end of each week, they reported their headache durations and any side effects to the clinic. After four weeks of follow up of the last patient, the sealed codes were decoded. This kind of data collected from one patient at several time points is called longitudinal data. A variety of statistical methods are suggested for analyzing longitudinal data including linear mixed models or marginal models, using generalized estimating equations.

In the first stage, we applied a linear mixed model to fit the data. In order to check the adequacy of the model, we plot normal quantile and box plot of the standardized deleted residuals which showed the existence of skewness and outlier respectively. By plotting standardized deleted residuals against predicted values for this model, nonconstant error variance was apparent, which confirms that the applied model was not appropriate. One approach to solve these problems is finding outliers and introducing them to the model as dummy variables so as to consider their effects. We applied this method, but the mentioned plots did not change considerably. Another approach is adding a random effect for the group variable in the model in order to consider heteroskedasticity. Heteroskedasticity happens when the assumption of homoscedasticity is violated. These problems were not solved through these methods.

The third approach is applying appropriate distribution for the outcome variable. The histogram of the response variable depicted in Figure 1 shows a non-normal distribution. Goodness of fit test for normal distribution (Kolmogorov-Smirnov $\mathrm{D}$ test, $\mathrm{p}<0.01$ ) also confirmed that our data were not distributed normally.

As mentioned earlier, the outcome variable in this study



Fig. 1. Histogram of the duration of migraine attacks

has two distinctive features, which make the above approaches inappropriate. Firstly, a great number of zeros and secondly, positive values which are skewed. Statisticians call these kinds of data semi-continuous. Statistical approaches assuming normal distribution for the outcome are inappropriate, because these methods do not consider excess zeros as well as the tendency of positive values to skewness. Furthermore, recoding the outcome into a dichotomous variable omits useful information. So, to deal with such data, two-part models were proposed. These models consider both zero part and positive part of the data in a united model. We applied probit/log-skewnormal mixture model, as a special case, to take these characteristics into account (25).

\section{Statistical Analysis}

If $Y_{i j}$ denotes a measurement related to $i_{t h}$ subject in time $j$ and $Y_{i j} \geq 0$ and define $I_{i}$ as an indicator function $I_{i}=\left\{\begin{array}{ccc}1 & \text { if } & Y_{i j}=0 \\ 0 & \text { if } & Y_{i j} \neq 0\end{array}\right.$, the probability density function of $Y_{i j}$ in probit log skew normal model is:

$f\left(y_{i j}\right)=I_{i} P\left(Y_{i j}=0\right)+P\left(Y_{i j}>0\right) f\left(Y_{i j} \mid Y_{i j}>0\right)$

The probit link function was used for $\left(Y_{i j}=0\right)$ :

$P\left(Y_{i j}=0\right)=\Phi\left(-X_{(1) i j}^{T} \beta_{(1)}\right) \quad, x_{(1) i j} \subseteq x_{i j}, \beta_{(1)} \subseteq \beta$

Where $\Phi$ is the standard normal cumulative distribution function (cdf), $X_{(1) i j}$ is a vector of covariates, and $\beta_{(1)}$ is a vector of regression parameters.

Skew normal distribution was also used for the logarithm of all positive responses.

$\log \left(y_{i j} \mid y_{i j}>0\right) \sim S N\left(X_{(2) i j}^{T} \beta_{(2)}, \sigma, \delta\right) \quad, X_{(2) i j} \subseteq x_{i}, \beta_{(2)} \subseteq \beta$

$X_{(2) i j}$ is the vector of covariates associated with the duration of migraine attacks for the $i_{\text {th }}$ subject in $j_{\text {th }}$ week. $\beta_{(2)}$ is the vector of regression parameters in positive response part of the model.

We have applied the above statistical model to assess the effect of explanatory variables on the duration of migraine attacks. Factors having influence on the probability of being migraine free were also recognized. SAS software, version 9.4 was used for fitting the model. P-value less than 0.05 was considered significant. 


\section{Results}

In our study, as Table 1 shows, among 68 patients included in the analysis, $77.3 \%(n=51)$ of patients in both groups were female and $22.7 \%(n=15)$ were male. Mean age in intervention and placebo groups were $33.09 \pm 7.5$ and $31.03 \pm 7.2$ years, respectively. Among all patients, $83.3 \%(n=55)$ had migraine without aura - more than $80 \%$ in each group. The trends of migraine duration across groups are illustrated in Table 2. Although migraineurs in intervention groups experienced substantially longer migraine attacks on average compared to place group - about 24 hours and 15 hours per week respectively-they had a considerably shorter migraine at the end of the study.

Table 2 shows that the mean of migraine duration has reduced more than 23 hours from baseline until the $4^{\text {th }}$ week of study in the intervention group, while it experienced only 10 hours reduction in the placebo group over our study. Figure 2 also illustrates these differences.

In general, the effect of coriander fruit on the duration of migraine attacks was assessed using probit/log skewnormal model. Table 3 shows the results of fitting the final mixture model to migraine data. The interaction between time and group variable was significantly associated with the probability of having no migraine attack (probit submodel). It indicates that the probability of being migraine free was considerably higher in the final weeks of the study (beta $=-0.496, p<0.001$ ) in the intervention group compared to the placebo group.

Figure 3 confirms this result. This figure illustrates that the probability of having no migraine attack in the intervention group increased considerably more than the placebo group during the study. As Table 4 illustrates although the probability of becoming migraine-free was 0.0001 in baseline in both treatment groups, these probabilities increased to more than 0.84 and just over 0.17 in intervention and placebo groups, respectively.

Duration of migraine attacks was also associated with weeks of follow-up, and the interaction between the week of follow-up and treatment group. It reveals that migraine duration in migraineurs using coriander fruit syrup reduced considerably during the study $(\mathrm{p}<0.001$, beta $=-0.471)$.
Migraine duration trend over time

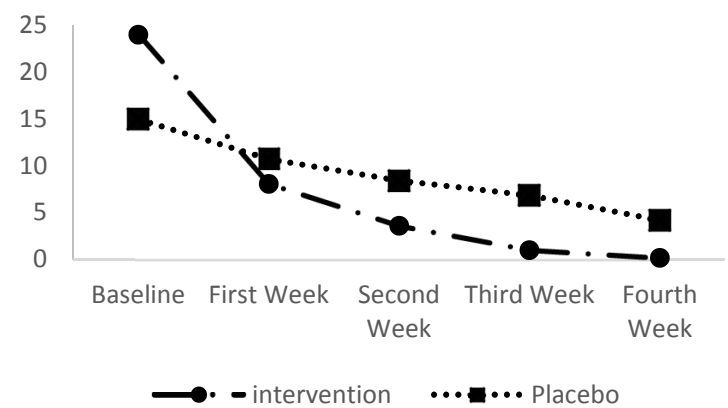

Fig. 2. Migraine durations' trends across treatment groups

It can also be inferred from Table 3 that years from the onset had positive significant effects on migraine duration $(\mathrm{p}=0.0004$, beta $=0.076$ ), which means that people diagnosed with migraine for a longer time suffered headache for more hours. Skewness parameter reported as $\delta$ in this table was highly significant $(\mathrm{p}=0.001$, estimated $\delta=-0.401)$

This result approved using a model which considers skewness. To test the hypothesis: $H_{0}: \delta=0$, our final model has also been compared with probit/log-normal model using the likelihood ratio test. Chi-square test statistics of the likelihood ratio is equal to $11.6, \mathrm{p}<0.001$.

In addition to regression coefficients and their standard errors, Table 3 contains other parameters, each of which possesses a special feature. For instance, the variances of random effects in the two model components - $S_{11}$ and $S_{22}$ - were highly significant indicating the random effects were required to consider the correlations among measurements of the same migraineur in the model $(\mathrm{p}<0.001)$.

The negative covariance between the two random effects has an appealing interpretation: the longer the migraine duration, the lower the probability of becoming migraine-free $\left(S_{12}=-0.014, P=0.905\right)$. However, this parameter estimate is not statistically significant in our model. In addition, AIC and BIC were both smaller in

Table 1. Demographic characteristics of patients in the study

\begin{tabular}{|c|c|c|c|c|c|}
\hline Variable & Category & Intervention & Control & Total & $\mathrm{p}$ \\
\hline \multirow[t]{2}{*}{ Gender $^{\dagger}$} & Female & $26(78.79)$ & $25(75.76)$ & $51(77.27)$ & 0.769 \\
\hline & Male & $7(21.21)$ & $8(24.24)$ & $15(22.73)$ & \\
\hline \multirow[t]{2}{*}{ Marital status ${ }^{\dagger}$} & Single & $9(27.27)$ & $15(45.45)$ & $24(36.36)$ & 0.125 \\
\hline & Married & $24(72.73)$ & $18(54.55)$ & $42(63.64)$ & \\
\hline \multirow[t]{2}{*}{ Type of migraine $^{\dagger}$} & Without Aura & $27(81.82)$ & $28(84.85)$ & $55(83.33)$ & 0.741 \\
\hline & With Aura & $6(18.18)$ & $5(15.15)$ & $11(16.67)$ & \\
\hline $\operatorname{Age}^{\ddagger}$ (year) & & $33.09 \pm 7.51$ & $31.03 \pm 7.20$ & $32.06 \pm 7.37$ & 0.259 \\
\hline \multicolumn{6}{|l|}{$\begin{array}{l}\dagger \text { Number (\%) } \\
\text { † Mean } \pm \text { sd }\end{array}$} \\
\hline Time & & Interventi & & Placehor & \\
\hline Baseline & & $23.94 \pm$ & & $14.94 \pm$ & \\
\hline First Week & & $8.03 \pm$ & & $10.7 \pm$ & \\
\hline Second Week & & $3.57 \pm$ & & $8.4 \pm 5$ & \\
\hline Third Week & & $0.98 \pm$ & & $6.84 \pm$ & \\
\hline Fourth Week & & $0.15 \pm$ & & $4.17 \pm 3$ & \\
\hline
\end{tabular}

Data are presented as mean $\pm \mathrm{SD}$ 
Table 3. Results of probit and log skew normal sub-models

\begin{tabular}{|c|c|c|c|c|}
\hline & Probit & $\mathrm{p}$ & Log-skew normal & $\mathrm{p}$ \\
\hline$\overline{\beta_{0}}$ & $5.033(0.906)^{*}$ & $<.0001$ & $2.866(0.191)$ & $<.0001$ \\
\hline$\beta_{W e e k}$ & $-0.857(0.177)$ & $<.0001$ & $-0.248(0.024)$ & $<.0001$ \\
\hline$\beta_{\text {Week } \times \text { Intervention }}$ & $-0.496(0.112)$ & $<.0001$ & $-0.47(0.039)$ & $<.0001$ \\
\hline$\beta_{\text {migraine without Aura }}$ & $0.932(0.532)$ & 0.085 & $0.083(0.216)$ & 0.7020 \\
\hline$\beta_{\text {years from onset }}$ & $0.054(0.044)$ & 0.228 & $0.076(0.021)$ & 0.0004 \\
\hline$\beta_{\text {Female }}$ & $-0.262(0.405)$ & 0.519 & $-0.159(0.194)$ & 0.4130 \\
\hline$\sigma^{\dagger}$ & & & $0.384(0.051)$ & $<.0001$ \\
\hline$\delta \ddagger$ & & & $-0.401(0.119)$ & 0.0010 \\
\hline$S_{11}{ }^{*}$ & $0.681(0.482)$ & 0.162 & & \\
\hline$S_{22}{ }^{*}$ & & & $0.375(0.079)$ & $<.0001$ \\
\hline$S_{12}{ }^{\times}$ & & & $-0.014(0.121)$ & 0.9050 \\
\hline-2 Log Likelihood & \multicolumn{2}{|c|}{606.300} & & \\
\hline $\mathrm{AIC}^{¥}$ & \multicolumn{2}{|c|}{640.300} & & \\
\hline $\mathrm{BIC}^{\S}$ & \multicolumn{2}{|c|}{677.500} & & \\
\hline
\end{tabular}

*Parameter estimates (Standard Error)

$\dagger$ Scale parameter of the model

\$Skewness parameter

* Random effects variance

$\times$ Random effects covariance

$¥$ Akaike Information Criteria

$\S$ Bayesian Information Criteria

Table 4. Probability of becoming migraine-free across treatment groups

\begin{tabular}{|c|c|c|c|c|c|}
\hline \multirow{4}{*}{$\begin{array}{l}\text { Treatment } \\
\text { Intervention } \\
\text { Placebo }\end{array}$} & \multicolumn{5}{|c|}{ Time } \\
\hline & Baseline & $1^{\text {st }}$ week & $2^{\text {nd }}$ week & $3^{\text {rd }}$ week & $4^{\text {th }}$ week \\
\hline & 0.0001 & 0.0078 & 0.1066 & 0.4559 & 0.8408 \\
\hline & 0.0001 & 0.0014 & 0.0107 & 0.0521 & 0.1736 \\
\hline
\end{tabular}

our model compared to probit log-normal model confirming the superiority of our model.

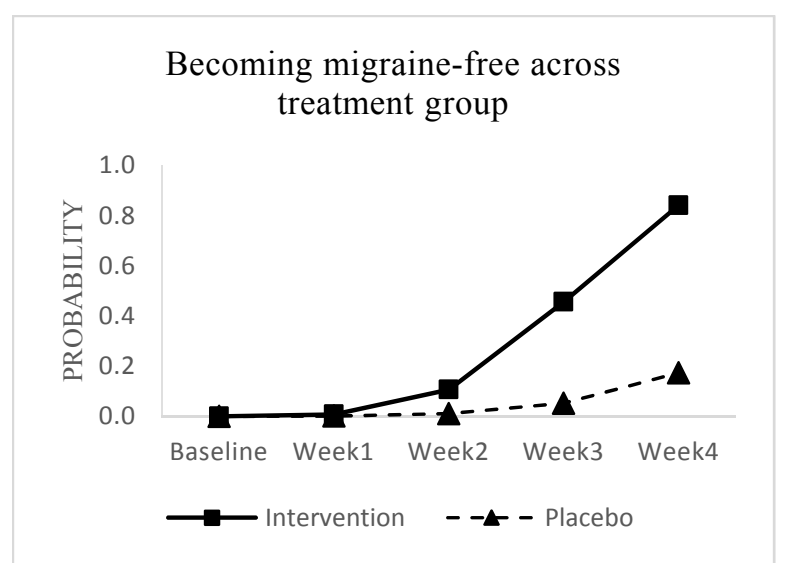

Fig. 3. Probability trends of becoming migraine-free across treatment groups



Fig. 4. Probability trends of becoming migraine-free across age and intervention categories
We applied our statistical model in migraineurs younger than 30 years old and equal to or more than 30 years old separately. Our model showed that the duration of migraine attacks of patients in the intervention group decreased considerably compared to the placebo group in both age categories.

However, as Table 4 illustrates, the coriander syrup has a more healing impact on patients less than 30 years old, especially in the last week of their treatment period. We approved this finding using independent sample t-test to compare the probability of becoming migraine-free in these age groups $(p<0.001)$. Figure 4 and Table 5 demonstrates this difference clearly.

Moreover, some marginal evidence revealed that the probability of being migraine-free in migraineurs without Aura is greater than migraineurs with aura which is shown in Figure 5 and Table 6.

Probability of becoming migraine-free across treatment group and migraine type

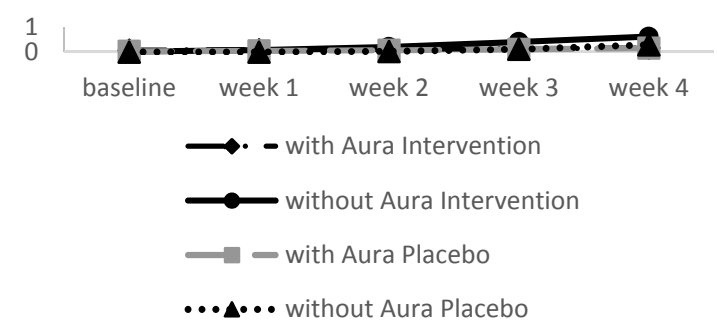

Fig. 5. Probability trends of becoming migraine-free across treatment groups and migraine type 
Table 5. Probability of becoming migraine-free across age and treatment groups

\begin{tabular}{lcccccc}
\hline Age groups & Treatment & \multicolumn{4}{c}{ Time } \\
\cline { 3 - 7 } & & Baseline & $1^{\text {st }}$ week & $2^{\text {nd }}$ week & $3^{\text {rd }}$ week & $4^{\text {th }}$ week \\
Less than 30 years old & Intervention & 0.0000 & 0.0000 & 0.0762 & 0.6186 & 1 \\
More than or equal 30 years old & Intervention & 0.0015 & 0.0191 & 0.1160 & 0.3724 & 0.7049 \\
Less than 30 years old & Placebo & 0.0000 & 0.0000 & 0.0000 & 0.1552 & 0.2622 \\
More than or equal 30 years old & Placebo & 0.0002 & 0.0015 & 0.0070 & 0.0259 & 0.0752 \\
\hline
\end{tabular}

Table 6. Probability of becoming migraine-free across migraine type and treatment groups

\begin{tabular}{|c|c|c|c|c|c|c|}
\hline \multirow[t]{2}{*}{ Migraine type } & \multirow[t]{2}{*}{ Treatment } & \multicolumn{5}{|c|}{ Time } \\
\hline & & Baseline & $1^{\text {st }}$ week & $2^{\text {nd }}$ week & $3^{\text {rd }}$ week & $4^{\text {th }}$ week \\
\hline Migraine with Aura & Intervention & 0.0724 & 0.0900 & 0.1106 & 0.1343 & 0.1614 \\
\hline Migraine without Aura & Intervention & 0.0196 & 0.0762 & 0.2067 & 0.4082 & 0.6208 \\
\hline Migraine with Aura & Placebo & 0.0275 & 0.0454 & 0.0717 & 0.1082 & 0.1565 \\
\hline Migraine without Aura & Placebo & 0.0000 & 0.0010 & 0.0222 & 0.1105 & 0.2900 \\
\hline
\end{tabular}

\section{Discussion}

Migraine attacks can affect migraineurs' routine activities in their most productive years of life. It can even lead to social and economic ramifications for governments. In studies concentrating on estimating indirect cost and burden of migraine, the missed workdays and impaired work performance were used (26). Moreover, in order to calculate the lost-labor cost, which is the monthly cost of reduced productivity attributable to working with migraine, the frequency of migraine attacks as well as the number of hours they worked with migraine each time they had a migraine attack per month were estimated (27). So, not only it is important to reduce migraine duration, but also finding a treatment through which migraineurs could become migraine-free is crucial. Coriander fruits extract as an herbal treatment in traditional Persian medicine was commonly prescribed to treat headaches (12).

In most cases, researchers apply less sophisticated statistical methods, such as GEE, to evaluate the effect of the intervention on their outcomes (24). Although they can illustrate that their intervention has a desirable effect, they do not pay attention to their data characteristics. In our study, not only the effect of coriander syrup on migraine duration has been assessed, but also through using our statistical model, we determined factors influencing on becoming migraine free. We applied a mixture model, which calculated this effect. Moreover, we considered the correct distribution of the data, which results in more accurate inferences $(25,28)$.

Our findings revealed that this plant could significantly reduce migraine duration and considerably increase the probability of being migraine-free that is in accordance with the study in Sri Lanka reporting the analgesic effect of coriander on human, which is used in a traditional formula called Maharasnadhi Quather (MRQ) (29).

In a study on adult mice, the effect of linalool to manage persistent pain has been illustrated (30). This study showed that chronic pain could be relieved through the hindrance of nociception evoked inflammatory mediators. In some other studies, the significant effect of essential oil of lavender on migraine, which contains a large amount of linalool was also illustrated (31). Since in our study the main component with the highest proportion was linalool, the existence of linalool in both coriander and lavender, because of its sedative effect could describe their efficiency on treating migraine (32).
Moreover, linalool has been recognized as an agonist of one of the transient receptor potential family - TRPM8 activated by low temperatures and cooling agents (33). Studies conducted on this gene revealed that it could be one of the migraine probable genes (34).

A placebo-controlled trial study on the extract of a special butterbur root for prevention of migraine on 60 patients suffering from migraine demonstrated a significant effect of this plant on reducing the number of migraine attacks (35). It can be caused by the anti-inflammatory effect of its main ingredients, such as petasin and isopetasin (36). This anti-inflammatory feature can also be seen in coriander in many studies (37). It could describe the effectiveness of this herbal treatment. Feverfew, coriander, and lavender reduce the frequency of migraine attacks through decreasing nitric oxide production level in their brain. Although nitric oxide is essential for the human body, its high level can cause migraine attacks (38).

Fortunately, we do not have any observed or recorded side effects. This could be because of the fact that our population is young and healthy with a mean age of 32 years old. Another reason might be because of-our short follow-up time. Our subjects received the placebo or coriander syrup for only one month. Therefore, one of the limitations of our study is that the long-term efficacy of coriander could not be discussed in our study. Since a reliable method to evaluate the efficacy and safety of a herbal drug is to conduct several well-designed clinical trials (10), it is suggested to perform clinical trial studies with larger sample size and longer periods for follow-up in different regional areas which will assist researchers in generalizing their findings to a wider population.

\section{Conclusion}

All in all, our study revealed that coriander could have short-term effects on reducing the risk of migraine attacks as well as migraine attacks' duration and frequency, especially in migraineurs less than 30 years old. Thus, it could be considered as a probable effective treatment for migraine without having the side effects of chemical drugs.

\section{Conflict of Interests}

The authors declare that they have no competing interests. 


\section{References}

1. Ghorbanifar Z, Delavar Kasmaei H, Minaei B, Rezaeizadeh H, Zayeri F. Types of nasal delivery drugs and medications in Iranian traditional medicine to treatment of headache. Iran Red Crescent Med J. 2014;16(6):e15935.

2. Vos T, Flaxman AD, Naghavi M, Lozano R, Michaud C, Ezzati M, et al. Years lived with disability (YLDs) for 1160 sequelae of 289 diseases and injuries 1990-2010: A systematic analysis for the Global Burden of Disease Study 2010. Lancet. 2013;380(9859):2163-2196.

3. Zhang Q, Wu Q, Zhang J, He L, Huang J, Zhang J, et al. Discriminative analysis of migraine without aura: using functional and structural MRI with a multi-feature classification approach. PLoS One. 2016;11(9):e0163875.

4. Bet PM, Hugtenburg JG, Penninx BWJH, Hoogendijk WJG. Side effects of antidepressants during long-term use in a naturalistic setting. Eur Neuropsychopharmacol. 2013;23(11):1443-1451.

5. Ramakrishnappa SK, Belhekar MN. Serum drug level-related sodium valproate-induced hair loss. Indian J Pharmacol. 2013;45(2):187-188.

6. Chen B, Choi H, Hirsch LJ, Moeller J, Javed A, Kato K, et al. Cosmetic side effects of antiepileptic drugs in adults with epilepsy. Epilepsy Behav. 2015;42:129-137.

7. Ferguson JM. SSRI antidepressant medications: Adverse effects and tolerability. Prim Care Companion J Clin Psychiatry. 2001;3(1):2227.

8. Miller S. The acute and preventative treatment of episodic migraine. Ann Indian Acad Neurol. 2012;15(Suppl 1):S33-S39.

9. Kamali SH, Khalaj AR, Hasani-Ranjbar S, Esfehani MM, Kamalinejad M, Soheil O, et al. Efficacy of 'Itrifal Saghir', a combination of three medicinal plants in the treatment of obesity: A randomized controlled trial. DARU J Pharm Sci 2012;20(1):33.

10. Pal SK, Shukla Y. Herbal medicine: Current status and the future. Asian Pac J Cancer Prev. 2003;4(4):281-8.

11. Zarshenas MM, Petramfar P, Firoozabadi A, Moein MR, Mohagheghzadeh A. Types of headache and those remedies in traditional persian medicine. Pharmacogn Rev. 2013;7(13):17-26.

12. Ibn-e-Sina AH. Al-qanun fit-tib [The canon of medicine]. Beirut: Alamle-al-Matbooat Inst; 2005.

13. de Almeida Melo E, Bion FM, Filho JM, Guerra NB. In vivo antioxidant effect of aqueous and etheric coriander (Coriandrum sativum L.) extracts. Eur J Lipid Sci Technol. 2003;105(9):483-487.

14. Emamghoreishi M, Khasaki M, Fath Aazam M. Coriandrum sativum: Evaluation of its anxiolytic effect in the elevated plus-maze. J Ethnopharmacol. 2005 Jan 15;96(3):365-70.

15. dos Santos P, Dutra JV, Delarmelina J, Tose L, Romão W, Jamal C, et al. Coriandrum sativum grown under organic or chemical fertilizer effectively prevents DNA damage: Preliminary phytochemical screening, flavonoid content, ESI (-) FTICR MS, in vitro antioxidant and in vivo (mice bone marrow) antimutagenic activity against cyclophosphamide. Asian Pac J Trop Biomed. 2018;8(6):292.

16. Messaoudi M, Begaa S. Dietary intake and content of some micronutrients and toxic elements in two Algerian spices (Coriandrum sativum L. and Cuminum cyminum L.). Biol Trace Elem Res. 2019;188(2):508-13.

17. Laribi B, Kouki K, M'Hamdi M, Bettaieb T. Coriander (Coriandrum sativum L.) and its bioactive constituents. Fitoterapia. 2015;103:9-26.

18. Daly T, Jiwan MA, O'Brien NM, Aherne SA. Carotenoid content of commonly consumed herbs and assessment of their bioaccessibility using an in vitro digestion model. Plant Foods Hum Nutr. 2010;65(2):164-169.

19. Puthusseri B, Divya P, Veeresh L, Kumar G, Neelwarne B. Evaluation of folate-binding proteins and stability of folates in plant foliages. Food Chem 2018;242:555-559.

20. Guenther E. The essential oils. New York : D Van Nostrand Company; 1948.

21. Mani V, Parle M, Ramasamy K, Abdul Majeed AB. Reversal of memory deficits by Coriandrum sativum leaves in mice. J Sci Food Agric. 2011;91(1):186-192.

22. Cioanca O, Hritcu L, Mihasan M, Hancianu M. Cognitiveenhancing and antioxidant activities of inhaled coriander volatile oil in amyloid $\beta(1-42)$ rat model of Alzheimer's disease. Physiol Behav. 2013;120:193-202.

23. Emamghoreishi M. Sedative-hypnotic activity of extracts and essential oil of coriander seeds. Iran J Med. 2015;31(1):22-27.
24. Delavar Kasmaei H, Ghorbanifar Z, Zayeri F, Minaei B, Kamali $\mathrm{SH}$, Rezaeizadeh $\mathrm{H}$, et al. Effects of Coriandrum sativum syrup on migraine: A randomized, triple-blind, placebo-controlled trial. Iran Red Crescent Med J. 2016;18(1):e20759.

25. Mahmud S, Lou WW, Johnston NW, Smith S, Schreiber J, Johnston $\mathrm{S}$, et al. A probit- log- skew-normal mixture model for repeated measures data with excess zeros, with application to a cohort study of paediatric respiratory symptoms. BMC Med Res Methodol. 2010;11(1):327-339.

26. Hawkins K, Wang S, Rupnow MFT. Indirect cost burden of migraine in the United States. J Occup Environ Med. 2007;49(4):368374.

27. Osterhaus JT, Gutterman DL, Plachetka JR. Healthcare resource and lost labour costs of migraine headache in the US. Pharmacoeconomics. 1992;2(1):67-76.

28. Tooze JA, Grunwald GK, Jones RH. Analysis of repeated measures data with clumping at zero. Stat Methods Med Res. 2002;11(4):34155.

29. Thabrew MI, Dharmasiri M, Senaratne L. Anti-inflammatory and analgesic activity in the polyherbal formulation Maharasnadhi Quathar. J Ethnopharmacol. 2003;85(2-3):261-267.

30. Batista PA, de Paula Werner MF, Oliveira EC, Burgos L, Pereira P, da Silva Brum LF, et al. The antinociceptive effect of (-)-Linalool in models of chronic inflammatory and neuropathic hypersensitivity in mice. J Pain. 2010;11(11):1222-1229.

31. Rafie S, Namjoyan F, Golfakhrabadi F, Yousefbeyk F, Hassanzadeh A. Effect of lavender essential oil as a prophylactic therapy for migraine: A randomized controlled clinical trial. J Herb Med. 2016;6(1):18-23.

32. Re L, Barocci S, Sonnino S, Mencarelli A, Vivani C, Paolucci G, et al. Linalool modifies the nicotinic receptor-ion channel kinetics at the mouse neuromuscular junction. Pharmacol Res. 2000;42(2):177-181.

33. Behrendt HJ, Germann T, Gillen C, Hatt H, Jostock R. Characterization of the mouse cold-menthol receptor TRPM8 and vanilloid receptor type-1 VR1 using a fluorometric imaging plate reader (FLIPR) assay. Br J Pharmacol 2004; 141(4): 737-745.

34. Dussor G, Cao YQ. TRPM8 and Migraine. Headache J Head Face Pain. 2016;56(9):1406-1417.

35. Diener HC, Rahlfs VW, Danesch U. The first placebo-controlled trial of a special butterbur root extract for the prevention of migraine: Reanalysis of efficacy criteria. Eur Neurol. 2004;51(2):89-97.

36. Thomet OA, Wiesmann UN, Blaser K, Simon HU. Differential inhibition of inflammatory effector functions by petasin, isopetasin and neopetasin in human eosinophils. Clin Exp Allergy. 2001;31(8):1310-1320.

37. Mahendra P, Bisht S. Anti-anxiety activity of Coriandrum sativum assessed using different experimental anxiety models. Indian J Pharmacol. 2011 Sep;43(5):574-577.

38. Ansari M, Rafiee K, Emamgholipour S, Fallah MS. Migraine: Molecular Basis and Herbal Medicine. Advanced Topics in Neurological Disorders. London: InTechOpen; 2012. p. 187-214. 